This item was submitted to Loughborough's Research Repository by the author.

Items in Figshare are protected by copyright, with all rights reserved, unless otherwise indicated.

\title{
Revisiting the twin deficits hypothesis: new evidence from nonlinear tests
}

PLEASE CITE THE PUBLISHED VERSION

https://doi.org/10.1080/13504851.2019.1707473

PUBLISHER

Taylor \& Francis (Routledge)

VERSION

AM (Accepted Manuscript)

PUBLISHER STATEMENT

This is an Accepted Manuscript of an article published by Taylor \& Francis in Applied Economics Letters on 24 December 2019, available online: http://www.tandfonline.com/10.1080/13504851.2019.1707473.

\section{LICENCE}

CC BY-NC-ND 4.0

\section{REPOSITORY RECORD}

Ahmad, Ahmad Hassan, and Olalekan B Aworinde. 2019. "Revisiting the Twin Deficits Hypothesis: New Evidence from Nonlinear Tests”. Loughborough University. https://hdl.handle.net/2134/11347142.v1. 


\title{
Revisiting the Twin Deficits Hypothesis: New Evidence from Nonlinear Tests*
}

\author{
Ahmad Hassan Ahmad ${ }^{\dagger \ddagger} \quad$ Olalekan B. Aworinde ${ }^{\S}$
}

\begin{abstract}
This paper investigates linear and nonlinear causal linkages between fiscal deficits and current account deficits in a sample of twelve African countries using quarterly data for the period 1980:1-2018:4. The results indicate evidence of unidirectional causality from current account deficits to the fiscal deficits in four countries while a unidirectional causality from fiscal deficit to current account deficit is found in five countries. Results from panel causality test revealed evidence of bidirectional causality between the two deficits. These conclusions suggest that policy to tackle one of the deficits should also take the other into consideration.
\end{abstract}

Key Words: Fiscal deficits; Current account deficits; nonlinear causality; African countries

JEL Classification: H60, H62, C22, C23

${ }^{*}$ We are very grateful to the editor and the anonymous reviewer for the useful and constructive comments.

${ }^{\dagger}$ Corresponding author.

${ }^{\ddagger}$ School of Business \& Economics, Loughborough University, Leicestershire, LE11 3TU, United Kingdom. A.H.Ahmad@lboro.ac.uk

${ }^{\S}$ Department of Economics, School of Management \& Social Sciences Pan-Atlantic University, Lagos, Nigeria 


\section{Introduction}

The reoccurrence of large fiscal deficits and current account deficits in both developed and developing countries has generated interests among researchers not least because the control of these deficits is a necessary condition for sustainable economic growth. This has been further highlighted by the recent financial crisis that resulted in sovereign debts crisis of some European countries. African countries rely on a few numbers of primary commodities for their exports, which are very vulnerable to terms of trade shocks. These shocks have important effects on both the countries' current account balances as well as their public expenditure.

Relationship between fiscal and current account deficits has attracted enormous debate over the years, which are generally discussed within the absorption theory and the Mundell-Fleming framework. The former, suggests that an increase in the budget deficit would increase domestic absorption and hence import expansion and consequently increases current account deficit, i.e. the current account targeting hypothesis CATH). This could be particularly the case of small open economies like African countries that are highly depend on a few and un-diversified exports as noted above. The latter, on the other hand, argues that an increase in budget deficit would have upward pressure on interest rates, causing capital inflows and exchange rate appreciate that would negatively impact on current account. This is based on the Keynesian hypothesis.

Empirical results are mixed as Corsetti and Muller (2006), Salvatore (2006) and Baharumshah and Lau (2009), Grier and Ye (2009), Holmes (2011) and Mohammadi, et al..(2012) find that budget and current evidence that support the Keynesian hypothesis. By contrast, Kim and Roubini (2008), Marinheiro (2008) and Katircioglu et al (2009) results favour the (CATH). Islam (1998) and Kouassi et al. (2004), on the other hand, suggest bidirectional causality.

The main contributions of this paper are threefold. First, the paper applies and compares the obtained results from both linear and nonlinear models to African countries that have experienced both current account and fiscal deficits, which prompted economic reforms in the 1980s and 1990s, but have been largely overlooked by the previous literature. Secondly, paper uses the nonparametric methodology of Diks and Panchenko (2006), which overcame the potential over-rejection issue that flawed the famous non-linear Granger causality of Hiemstra and Jones (1994). Thirdly, we also examine the possibility of panel causality between the fiscal deficits and current account deficits in these countries.

The rest of the paper is organized as follows. Section 2 discusses the methodology used in the paper. Section 3 presents the data and analyses the estimated results while Section 4 concludes. 


\section{Methodology}

The study uses the nonparametric test of Diks and Panchenko (2006), DP, for testing nonlinear Granger causality between current account deficits and fiscal deficits in twelve African countries 1 . The test is an improvement over Hiemstra and Jones (1994), HJ, test that is found to be susceptible to over rejection. If $X_{t}$ and $Y_{t}$ (where $\mathrm{t}$ is assumed to be an integer) are strictly stationary time series processes, then $\left\{X_{t}\right\}$ is said to Granger cause $\left\{Y_{t}\right\}$ provided some $k \geq 1\left(Y_{t+1} \ldots, Y_{t+k}\right) \mid\left(F_{x, t}, F_{Y, t}\right)$ is not equivalent to $\left(Y_{t+1}, \ldots, Y_{t+k}\right) \mid\left(F_{y, t}\right) . F_{x, t}$ and $F_{Y, t}$ denote information set of $X$ and $Y$ at time t. In conducting Granger causality test, the objective is to look for evidence against the null:

$$
H_{0}:\left\{X_{t}\right\} \text { does not Granger cause }\left\{Y_{t}\right\} \text {. }
$$

In general, conditional independence is tested using finite lags $l x$ and $l_{y}$ as:

$$
Y_{t+1}\left|\left(X_{t}^{\ell_{X}} ; Y_{t}^{\ell_{Y}}\right) \sim Y_{t+1}\right| Y_{t}^{\ell_{Y}}
$$

For a strictly stationary bivariate time series Eq. (1) comes down to a statement about the invariant distribution of the $\left(\ell_{X}+\ell_{Y}+1\right)$-dimensional vector $\mathbf{W}_{\mathbf{t}}=\left(\mathbf{X}_{t}^{\ell_{X}}, \mathbf{Y}_{t}^{\ell_{Y}}, Z_{t}\right)$ where $Z_{t}=Y_{t+1}$. To keep the notation compact, and to bring about the fact that the null hypothesis is a statement about the invariant distribution of $\left(X_{t}^{\ell_{X}}, Y_{t}^{\ell_{Y}}, Z_{t}\right)$ we drop the time index and also $\ell_{X}=\ell_{Y}=1$ is assumed. Hence, under the null, the conditional distribution of $Z$ given $(X, Y)=(x, y)$ is the same as that of $Z$ given $Y=y$. Further, Eq. (1) can be restated in terms of ratios of joint distributions. Specifically, the joint probability density function $f_{X, Y, Z}(x, y, z)$ and its marginals must satisfy the following relationship:

$$
\frac{f_{X, Y, Z}(x, y, z)}{f_{Y}(y)}=\frac{f_{X, Y}(x, y)}{f_{Y}(y)} \cdot \frac{f_{Y, Z}(y, z)}{f_{Y}(y)}
$$

This explicitly states that $X$ and $Z$ are independent conditionally on $Y=y$ for each fixed value of $y$. Diks and Panchenko (2006) show that the reformulated $H_{0}$ implies:

$$
q=E\left[f_{X, Y, Z}(X, Y, Z) f_{Y}(Y)-f_{X, Y}(X, Y) f_{Y, Z}(Y, Z)\right]=0
$$

Let $\hat{f}_{W}(W i)$ denote a local density estimator of a $d_{W}$-variate random vector $\mathbf{W}$ at $W_{i}$ defined by $\hat{f}_{W}(W i)=\left(2 \varepsilon_{n}\right)^{-d_{W}}(n-1)^{-1} \Sigma j j \neq i I_{i j}{ }^{W}$ where $\operatorname{Iij}^{W}=$

\footnotetext{
${ }^{1} \mathrm{~A}$ linear Granger causality test based on VAR has also been used and the results are also reported in Table 1.
} 
$I\left(\left\|W_{i}-W_{j}\right\|<\varepsilon_{n}\right)$ with $I($.$) the indicator function and \varepsilon_{n}$ the bandwidth, depending on the sample size n. Given this estimator, the test statistic is a scaled sample version of $q$ in Eq. (3):

$$
T_{n}\left(\varepsilon_{n}\right)=\frac{n-1}{n(n-2)} \cdot \sum_{i}\left(\hat{f}_{X, Z, Y}\left(X_{i}, Z_{i}, Y_{i}\right) \hat{f}_{Y}\left(Y_{i}\right)-\hat{f}_{X, Y}\left(X_{i}, Y_{i}\right) \hat{f}_{Y, Z}\left(Y_{i}, Z_{i}\right)\right)
$$

For $\ell_{X}=\ell_{Y}=1$, if $\varepsilon_{n}=C n^{-\beta}\left(C>0, \frac{1}{4}<\beta<\frac{1}{3}\right)$ then Diks and Panchenko (2006) prove under strong mixing that the test statistic in Eq. (4) satisfies:

$$
\sqrt{n} \frac{\left(T_{n}\left(\varepsilon_{n}\right)-q\right)}{S_{n}} \underline{D} N(0,1)
$$

where $\underline{D}$ denotes convergence in distribution and $S_{n}$ is an estimator of the asymptotic variance of $T_{n}($.$) .$

\section{$3 \quad$ Data and the Estimated Results}

The data set is obtained from the Government Finance Statistics (GFS) and the Balance of Payment Statistics (BOPS) of the IMF as well as the World Bank Development Indicators. The fiscal deficit $2^{2}$ and the current account balance consist of quarterly observations covering 1980:1 to 2018:4, inclusive.

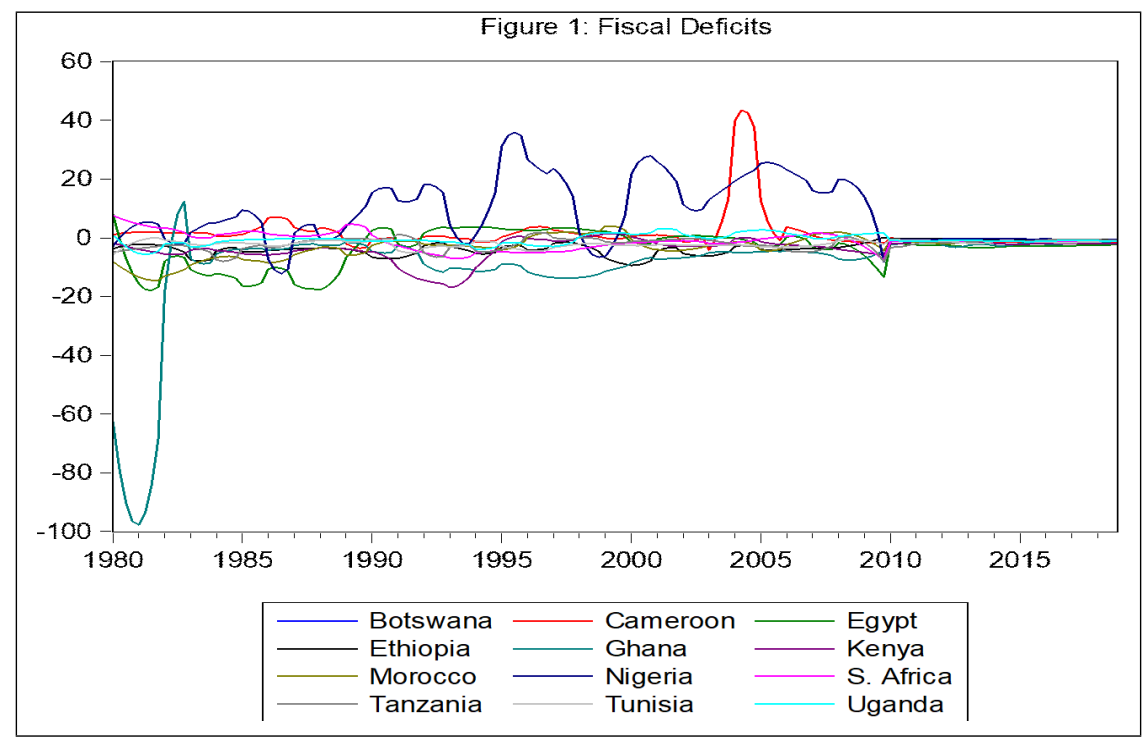

\footnotetext{
${ }^{2}$ For some countries where the fiscal deficits variable is not available, we used the fiscal deficits reported by the Central Banks of the countries.
} 
The fiscal deficit $(F D)$ is constructed as the difference between government total revenue and expenditure and expressed as a percentage of the respective countries' GDP. The current account balance $(C A B)$ is the sum of the balance of trade (exports minus imports of goods and services), net factor income (such as interest and dividends) and net transfer payments (such as foreign aid) also expressed as a percentage of the countries' GDP. The countries in the sample are Botswana, Cameroon, Egypt, Ethiopia, Ghana, Kenya, Morocco, Nigeria, South Africa, Tanzania, Tunisia, and Uganda. ${ }^{3}$

Figure 1 plots depicts fiscal deficits of the countries covered while Figure 2 provides the constructed current accounts of the countries. Both figures indicates how jumpy and volatile the series are, which reflects two things. First, fiscal policies are arbitrary and as such they are expected to be non-linear and secondly, trade balance that constituents bulk of the current accounts of the countries are dependent on a few primary commodities that are priced at international markets. These features of the series make it necessary to be modelled with linear and non-linear techniques $\stackrel{4}{\square}^{4}$

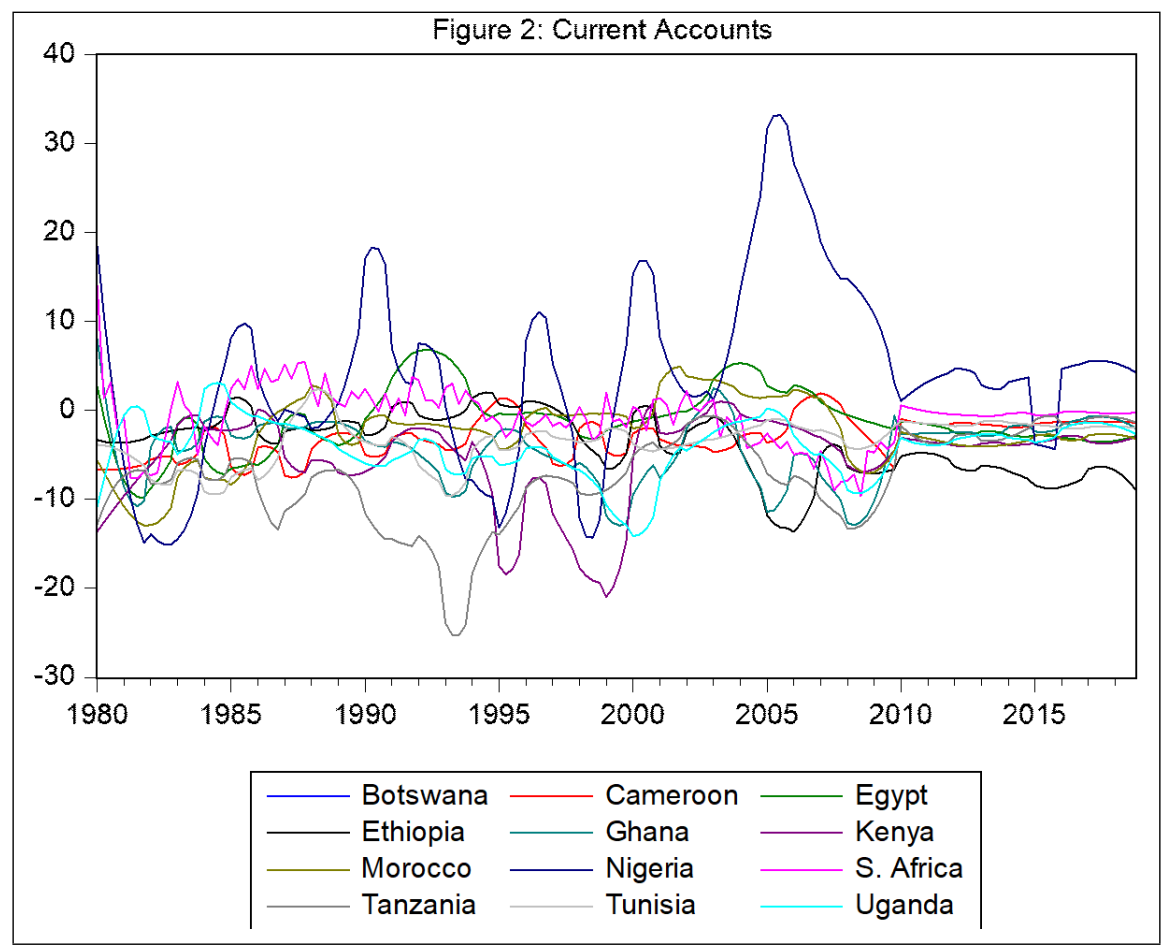

The parametric linear causality testing was carried out using the Granger's test

\footnotetext{
${ }^{3}$ These countries accounted for about 75 per cent of the African countries GDP in 2009 (Ahmad, Pentecost and Harvey, 2011).

${ }^{4}$ Further evidence on non-linearity of the series is evident in the summary statistics, which are not reported due to space limitation, but available in request.
} 
based on a VAR model. The lag lengths of the VAR specification were set using the information criteria and the series were also subjected to unit root tests. To implement the nonparametric causality test of DP, the study follows the suggestion of Diks and Panchenko (2006) by setting the bandwidth to 1.5. Table 1 present results from the linear and non-linear causality tests. The linear Granger tests show evidence of unidirectional causality from the current account deficits to the fiscal deficits only in Ethiopia and Tanzania. Evidence for a unidirectional causality from fiscal deficits to the current account deficits was found in Botswana, Egypt and Morocco.

The results for the unidirectional causality from current account to fiscal deficit is consistent with the current account targeting hypothesis while the ones from fiscal deficit to current account is in consonant to the Keynesian absorption theory. The nonlinear causality test revealed a bidirectional nonlinear relationship in Kenya, whereas in Nigeria, Tanzania and Tunisia unidirectional causality was detected from the current account deficits to the fiscal deficits. Also there is evidence of a unidirectional nonlinear relationship from the fiscal deficits to the current account deficits for Botswana, Ghana, Morocco and Uganda. This highlights importance of using both linear and non-linear models.

Following Bekiros and Diks (2008), we reapplied the linear causality and the non-parametric DP test to the residuals obtained from the VAR model to show that the detected causality was linear and nonlinear in nature. The results, as reported in part of Panels A and B of Table 1, indicate that there is linear unidirectional causality from current account to fiscal deficits in Botswana, Ghana and Morocco. The nonlinear test, on the other hand, suggests a unidirectional causality from current account to fiscal deficits in Ghana.

In addition, a panel causality test for the twelve countries was conducted. The test, which allows for heterogeneity in the coefficients and variances, capturing the economic diversities of the countries covered. Table 2 reports the results and it is evident that bidirectional causality relationship for the fiscal deficits and the current account deficits was found. Over all, the results suggest relationship between the two deficits in these countries, which may require a policy that can take both into consideration. 
Table 1: Causality Results (Pairwise)

\begin{tabular}{lllllllll}
\hline Countries & \multicolumn{3}{c}{ Panel A: Linear Granger Causality } & \multicolumn{3}{c}{ Panel B: Non-Linear Causality } \\
\hline & \multicolumn{3}{c}{ Data } & \multicolumn{3}{c}{ VECM Residuals } & \multicolumn{3}{c}{ Data } & \multicolumn{3}{c}{ VECM Residuals } \\
& CAB $\rightarrow$ FDFD $\rightarrow$ CABCAB $\rightarrow$ FDFD $\rightarrow$ CABCAB $\rightarrow$ FDFD $\rightarrow$ CABCAB $\rightarrow$ FDFD $\rightarrow$ CAB \\
Botswana & 8.89 & $13.31^{* *}$ & 9.12 & $23.45^{* * *}$ & -0.25 & $1.83^{* *}$ & 0.17 & -1.50 \\
Cameroon & 0.35 & 0.77 & 1.33 & 7.15 & 0.38 & 0.30 & -2.63 & -1.16 \\
Egypt & 2.47 & $67.15^{* * *}$ & 0.72 & 12.98 & 0.48 & 0.97 & -1.58 & 0.01 \\
Ethiopia & $11.17^{*}$ & 1.99 & 1.82 & 2.86 & 0.15 & 0.26 & 0.03 & -2.25 \\
Ghana & 0.22 & 7.95 & 8.52 & $19.32^{* *}$ & -0.67 & $1.38^{*}$ & -0.59 & $1.43^{*}$ \\
Kenya & 0.48 & 4.75 & 3.88 & 11.3 & $1.52^{*}$ & $1.94^{* *}$ & -1.08 & -1.35 \\
Morocco & 2.98 & $11.49^{* *}$ & 7.67 & $16.53^{* *}$ & 0.56 & $1.98^{* *}$ & -0.14 & -1.12 \\
Nigeria & 1.92 & 0.37 & 3.76 & 0.06 & $2.04^{* *}$ & 1.16 & -0.80 & -1.22 \\
South & 4.25 & 3.41 & 0.68 & 2.29 & 1.16 & 1.55 & 0.67 & -1.12 \\
Africa & & & & & & & & \\
Tanzania & $15.62^{* *}$ & 9.28 & 0.45 & 0.02 & $1.56^{* *}$ & 0.43 & -1.13 & 0.29 \\
Tunisia & 1.36 & 0.91 & 2.76 & 6.79 & $1.53^{*}$ & 1.24 & -0.23 & 0.82 \\
Uganda & 2.84 & 7.97 & 7.90 & 1.69 & 0.67 & $1.39^{*}$ & 0.11 & 0.39 \\
\hline
\end{tabular}

Note: $* * *, * *$ and $*$ denotes p-value statistical significance at 1,5 and 10 per cent respectively.

Panel A: Linear Granger Causality.

Panel B: Non-Linear Causality.

Table 2: Panel causality test allowing for heterogeneity in the coefficients and variances

\begin{tabular}{ll}
\hline Heterogenous Panel Causality Test & Statistic \\
\hline Current account deficits does not granger Cause fiscal deficits & $19.61^{* *}$ \\
Fiscal deficits does not granger Cause the current account deficits & $29.63^{* * *}$ \\
\hline
\end{tabular}

Note: ${ }^{* * *},{ }^{* *}$ and $*$ indicate level of significance at 1,5 and 10 per cent respectively. 


\section{Conclusion}

This paper investigates the existence of linear and nonlinear causal relationships between the fiscal deficits and the current account deficits in twelve African countries. The results show evidence of unidirectional causality from the current account deficits to the fiscal deficits in Ethiopia, Nigeria, Tanzania and Tunisia. A unidirectional causality from fiscal deficits to the current account deficits was found for Botswana, Egypt, Ghana, Morocco and Uganda.

Results from the panel causality test revealed evidence of bidirectional causality of the twin deficits in the countries. These conclusions, apart from offering a much better understanding of the dynamic linear and nonlinear relationships underlying the twin deficits hypothesis, may have important implications for government fiscal policy.

\section{References}

[1] Bekiros, S. D \& C Diks. 2008. "The relationship between crude oil spot and futures prices: Cointegration, linear and nonlinear causality." Energy Economics 30:2673-2685.

[2] Corsetti, Giancarlo \& Gernot J. Müller. 2006. "Twin deficits: squaring theory, evidence and common sense."Economic Policy 21(48):597-638.

[3] Diks, C. \& Panchenko, V. 2006. "A new statistic and practical guidelines for nonparametric Granger causality testing." Journal of Economic Dynamics \& Control 30:1647-1669.

[4] Grier, Kevin \& Haichun Ye. 2009. "Twin Sons Of Different Mothers: The Long And The Short of The Twin Deficits Debate."Economic Inquiry 47(4):625638.

[5] Holmes, Mark J. 2011. "Threshold cointegration and the short-run dynamics of twin deficit behaviour." Research in Economics 65(3):271-277.

[6] Islam, M. Faizul. 1998. "Brazil's twin deficits: An empirical examination." Atlantic Economic Journal 26(2):121-128.

[7] Katircioglu, Salih Turan, Sami Fethi \& Meryem Duygun Fethi. 2009. "Twin deficits phenomenon in small islands: an empirical investigation by panel data analysis." Applied Economics Letters 16(15):1569-1573. 
[8] Kim, Soyoung \& Nouriel Roubini. 2008. "Twin deficit or twin divergence? Fiscal policy, current account, and real exchange rate in the U.S." Journal of International Economics 74(2):362-383.

[9] Kouassi, Eugene, Mbodja Mougoué \& Kern O. Kymn. 2004. "Causality tests of the relationship between the twin deficits." Empirical Economics 29(3):503525 .

[10] Marinheiro, Carlos Fonseca. 2008. "Ricardian equivalence, twin deficits, and the Feldstein-Horioka puzzle in Egypt." Journal of Policy Modeling 30:10411056 .

[11] Mohammadi, Hassan \& Golaleh Moshrefi. 2012. "Fiscal policy and the current account new evidence from four East Asian countries." Applied Economics Letters 19(2):167-17

[12] Salvatore, Dominick. 2006. "Twin deficits in the G-7 countries and global structural imbalances." Journal of Policy Modeling 28(6):701-712. 